\title{
Information structure in language acquisition. Production and comprehension of (in)definite articles by German-speaking children
}

\author{
Julia FUCHS ${ }^{1 \star}$, Ulrike DOMAHS ${ }^{2}$, and Christina KAUSCHKE ${ }^{2}$ \\ ${ }^{1}$ Johannes Gutenberg-University Mainz, Germany and ${ }^{2}$ Philipps-University Marburg, Germany \\ ${ }^{*}$ Corresponding author: Dr. Julia Fuchs, Johannes Gutenberg-University Mainz, FB 05, Department of \\ English and Linguistics, Jakob-Welder-Weg 18, 55128 Mainz, fuchsj@uni-mainz.de
}

(Received 20 December 2018; revised 10 October 2019; accepted 8 February 2020; first published online 26 May 2020)

\begin{abstract}
The present study investigates the production and comprehension of indefinite and definite articles as markers of givenness by typically-developing German-speaking children, from the perspective of information structure theory. The study involves 93 typically-developing children aged four to seven years old with normal language-skills and 20 adults. The results of a story-narration task and a truth-value judgment task reveal that children have more problems with new than with given referents in production as well as comprehension suggesting a "given better than new"-pattern. These findings are explained in the context of perspective-taking capacities and cue weighting theory.
\end{abstract}

Keywords: information structure; givenness; (in)definite articles; language acquisition; pragmatics

\section{Introduction}

One of the child's tasks during language acquisition is to learn which linguistic means serve as markers of information structure. The basic idea behind the term INFORMATION STRUCTURE is that a speaker adapts his or her utterance to the momentary informational needs of the interlocutor. Information structure theory has described several language-independent dimensions including focus, topic and givenness, which are encoded language-specifically. Givenness means that a referent can have different givenness status depending on whether it is newly introduced into the discourse or already part of the common ground. In German, as in many other languages like English and French, the relevant information structural markers of givenness are indefinite and definite articles. The acquisition of indefinite and definite articles serving as markers of givenness has been addressed in a couple of studies investigating English, French, Italian and Dutch. However, the picture about the acquisition of markers of givenness emerging from these studies is far from being clear.

(C) The Author(s), 2020. Published by Cambridge University Press. This is an Open Access article, distributed under the terms of the Creative Commons Attribution-NonCommercial-NoDerivatives licence (http://creativecommons.org/ licenses/by-nc-nd/4.0/), which permits non-commercial re-use, distribution, and reproduction in any medium, provided the original work is unaltered and is properly cited. The written permission of Cambridge University Press must be obtained for commercial re-use or in order to create a derivative work. 
In addition, German as another Indo-European language has so far been neglected. Against this background, the present study investigates how German-speaking children produce and understand indefinite and definite articles serving as information structural markers of givenness. Thereby, this study offers answers to the question of how German-speaking children acquire this important linguistic capacity; moreover, the new data contributes to clarifying the heterogenous picture concerning the acquisition of indefinite and definite articles as markers of givenness in Indo-European languages.

\section{Theoretical background}

\section{Information structure and givenness}

Givenness is one of the central dimensions of information structure. Regarding the terminology, we follow the influential paper "Basic notions of information structure" by Krifka (2008) who uses the term GIVENNESS rather than the synonymous term information status. In the present paper, GIVENNESS refers to referential givenness and not relational givenness. Relational givenness "involves a partition of the semantic-conceptual representation of a sentence into two complementary parts, $\mathrm{X}$ and $\mathrm{Y}$, where $\mathrm{X}$ is what the sentence is about and $\mathrm{Y}$ is what is predicated about X" (Gundel, 2015, p. 589), whereas referential givenness "involves a relation between a linguistic expression and a corresponding non-linguistic entity in the speaker/hearer's mind, the discourse (model), or some real or possible world" (Gundel, 2015, p. 587). Early accounts (Chafe, 1976) characterized givenness as a dichotomy, a referent being either new or given. Subsequent accounts (for example, Ariel, 1988, 1990; Baumann \& Riester, 2012), however, postulated that givenness is a continuum rather than a twofold concept, involving intermediate stages located between new and given referents. Although there may be good reasons to adopt a continuum of referential givenness, the present study confines to the two relatively uncontroversial givenness status, namely the extreme poles of the continuum: new referents on the one hand and given referents on the other hand.

When talking about referents, a speaker continuously has to decide whether they are new or given from the perspective of his or her interlocutor. A competent speaker must not rely on his or her own perspective because this may lead to severe communication problems with respect to the introduction of referents that are de facto new to the interlocutor but known to the speaker. Rather, the speaker has to represent the knowledge state of the interlocutor and decide whether a referent represents new or given information from the perspective of that very interlocutor. In other words, new referents represent information that "the speaker assumes he is introducing into the addressee's consciousness by what he says" and given referents are "that knowledge which the speaker assumes to be in the consciousness of the addressee at the time of the utterance" (Chafe, 1976, p. 30). New referents can either be known to the speaker and unknown to the interlocutor - in this case, the term INDEFINITE REFERENTIAL is used; or they can be new to both the speaker and the hearer (INDEFINITE NON-REFERENTIAL), as in "My mother might build a house" (Schaeffer \& Matthewson, 2005, p. 57). New referents are discourse-new (mentioned for the first time in the discourse) and hearer-new (unknown to the interlocutor) (Prince, 1992). Given referents, on the other hand, are known to both speaker and hearer (hearer-old): for example, because they have been mentioned in the previous discourse (discourse-old).

The present paper focuses on new referents that are indefinite referential (known to the speaker, new to the interlocutor) and given referents that are discourse-old and hearer-old. 
Articles as markers of givenness in German

In German, new referents are generally introduced by indefinite noun phrases with a form of the indefinite article ein:

(1) Auf Burg Eulenstein hauste seit uralten Zeiten ein kleines Gespenst. (Preußler, 1966; example taken from Musan, 2010, p. 5)

(In Eulenstein Castle a little ghost lived for hundreds of years.)

In addition to the introduction of new referents, indefinite articles can also be interpreted in the sense of an existential quantifier: in this case, the indefinite noun phrase simply expresses that there is at least one entity with the relevant characteristics in the discourse model. Thus, the indefinite article is ambiguous: even though it is not usual to interpret an indefinite noun phrase in an anaphorical sense, it is, logically, not impossible to do so, as example (2) shows:

(2) A boy was flying his kite. Did a kite fly away? (answer "yes" possible)

(example taken from van Hout, Harrigan \& de Villiers, 2010, p. 1981)

Given referents can either be marked by a pronoun or by a definite noun phrase. In the present study, only definite articles are of interest:

(3) Vor dem Haus stand ein Koffer. Tim trug den Koffer hinein. (example taken from Musan, 2010, p. 10)

(In front of the house there was a suitcase. Tim carried the suitcase into the house.)

Thus, the child's task in language acquisition from the perspective of information structure is to realize that new referents are introduced with an indefinite article ("ein" or "eine" in German), and that definite articles are used to refer to given referents ("der", "die" or "das" in German).

\section{Acquisition of articles in German}

The acquisition of articles is a complex and multi-faceted task comprising functions linked to syntax, lexicon, morphology, and information structure. Children acquiring German first have to learn that an article is obligatory in a noun phrase, although there are some exceptions, e.g., in the case of mass nouns. They also have to store the gender of a noun and select an article in accordance with the noun's gender category (masculine, feminine, neuter). In addition, case marking interacts with gender, as shown in Table 1. The table demonstrates substantial homonymy of forms resulting in considerable ambiguity.

Of course, as function words, articles are among the most frequent words in a language. However, definite and indefinite articles are not equally frequent in German. Table 2 lists the frequency values for all article forms listed in Table 1, obtained from the FOLK-corpus (IDS, 2019) containing recordings of contemporary spoken German of more than 250 hours and about 2.4 million transcribed words (September 2019). The search mask allowed to specify that only articles are of interest (and not any homonymous forms like demonstrative pronouns). It turns out that in spoken German definite articles are of higher frequency than indefinite articles: 
Table 1. forms of the indefinite and definite article in German

\begin{tabular}{|c|c|c|c|c|c|c|c|}
\hline & \multicolumn{3}{|c|}{ indefinite article } & \multicolumn{4}{|c|}{ definite article } \\
\hline & \multicolumn{3}{|c|}{ singular } & \multicolumn{3}{|c|}{ singular } & plura \\
\hline nominative & ein & eine & ein & der & die & das & die \\
\hline accusative & einen & eine & ein & den & die & das & die \\
\hline genitive & eines & einer & eines & des & der & des & der \\
\hline
\end{tabular}


Table 2. relative frequencies per million words for all German article forms obtained from the FOLK-corpus

\begin{tabular}{lllllll}
\hline der & die & das & dem & den & des & mean \\
\hline 10643 & 13720 & 4555 & 3453 & 5180 & 614 & 6361 \\
\hline ein & eine & einem & einen & eines & einer & mean \\
\hline 6967 & 4972 & 776 & 2227 & 75 & 753 & 2628 \\
\hline
\end{tabular}

Despite their high frequency in the linguistic input, German-speaking children tend to omit articles in early stages of language development: Clahsen (1984) observed two boys in the age span from 1;5 to 3;5 and their sister from 2;0 to, 2;4 and found that these children overcame the initial stage of article omission when their MLU (in morphemes) reached, 2.75. In her longitudinal study with spontaneous speech from nine girls aged $1 ; 11$ to, 2;10 and further data from children until the age of three years, Bittner (1997) also observed an initial stage of article omission.

In a longitudinal study with spontaneous speech data from six children aged 1;4 to 3;8, Szagun, Stumper, Sondag and Franik (2007) found that when their subjects (five children between $1 ; 5$ and $1 ; 8$ and one child at 2;1) began to use articles, they differed considerably with respect to the acquisition sequence: two children used indefinite articles earlier than definite ones, whereas two other children showed the opposite sequence. Another two children of the sample started to use both article types simultaneously. Bittner (1997) and Mills (1986, p. 67) also found that children produced noun phrases with the indefinite article earlier than phrases with the definite one. Finally, Krüger (2017) found in her longitudinal corpus data of three children that one girl did not show a difference with respect to the onset of use of indefinite and definite articles, whereas another two girls used definite articles earlier than indefinite ones. To sum up, there is large individual variation with respect to the acquisition sequence with a slight tendency to an earlier onset of indefinite articles.

\section{Acquisition of indefinite and definite articles as markers of givenness}

The purpose of the following research overview is to offer a synopsis of previous studies on the acquisition of indefinite articles serving as markers of new referents (known to the speaker, but new to the interlocutor), and of definite articles serving as makers of given referents (discourse-old and hearer-old). Studies on other aspects of givenness (e.g., non-referential indefinites, intermediary stages of givenness) will not be reported. For the sake of comparability of results, languages in which the givenness of referents is not encoded by articles (e.g., Armon-Lotem \& Avram, 2005 on Hebrew) are not taken into account. Moreover, it is important to emphasize that not every study dealing with the acquisition of articles ensures that an alleged new referent is indeed hearer-new. For example, the elicitation of articles in the sentence completion tasks performed by Zehler and Brewer (1982) as well as van Hout et al. (2010) did not provide a situation in which children had to assume that the experimenter as a hearer is uninformed about the answer - therefore, there is no real discrepancy between the knowledge states of the participant and the hearer. There is also no necessity to mark a referent as hearer-new if the relevant referent is present in the shared visual context, as in Schaeffer and Matthewson's (2005) study. 
Table 3. Summary of research results on the comprehension and production of new and given referents

\begin{tabular}{|c|c|c|c|}
\hline & 'given better than new' & 'new better than given' & no preference/pattern \\
\hline$\frac{\text { ர் }}{\text { 음 }}$ & $\begin{array}{l}\text { Warden, } 1976 \\
\text { Emslie \& Stevenson, } 1981 \\
\text { Rozendaal \& Baker, } 2008\end{array}$ & $\begin{array}{l}\text { Schafer \& de Villiers, } 2000 \\
\text { Roth, } 2016 \\
\text { Chailleux, } 2017 \\
\text { de Cat, } 2011\end{array}$ & $\begin{array}{l}\text { Roth, } 2016 \\
\text { Chailleux, } 2017 \\
\text { Keydeniers et al., } 2017\end{array}$ \\
\hline ㅎํํ & $\begin{array}{l}\text { Maratsos, } 1976 \\
\text { van Hout et al., } 2008 \\
\text { van Hout et al., } 2010\end{array}$ & Karmiloff-Smith, 1979 & \\
\hline
\end{tabular}

The results of previous studies on the acquisition of indefinite and definite articles as markers of givenness show heterogeneous results (see Table 3): in some studies, indefinite articles as markers of new referents were more difficult to produce or understand than definite articles serving as markers of given referents ('given better than new'-pattern). In other studies, definite articles were more problematic than indefinite articles ('new better than given'-pattern). In addition, there are also studies that didn't find any preferences at all ('new as good as given').

With respect to the production of indefinite and definite articles serving as markers of givenness, the pattern 'given better than new' was mainly found by studies in which participants had to describe pictures or scenes: Warden (1976) conducted three experiments; since even adults did not consistently produce the target structures in the first two experiments, he developed a third one in which participants had to tell cartoon stories to another participant of the same age group. The results from children between three and nine years, revealing a 'given better than new'-pattern, showed that the children performed better with increasing age in marking new referents with indefinite articles. Emslie and Stevenson (1981) found that children aged, 2;2 to $4 ; 10$ as well as adults used indefinite and definite expressions mostly appropriately, even though definite expressions for given referents were used more consistently than indefinite articles for new referents. The pattern 'given better than new' was also confirmed in a corpus study by Rozendaal and Baker (2008) in which transcripts of the CHILDES database of Dutch-, English- and French-speaking children aged $2 ; 0$ to $3 ; 3$ were investigated. The very few occurrences of verbalized new referents were mostly not encoded adequately with indefinite articles; given referents, on the other hand, were more frequent and marked with definite articles around $60 \%$ of the time.

For comprehension, the pattern 'given better than new' was found by almost all studies: in Maratsos' (1976) experiment, participants were told stories and asked to use toys to act them out. Three- and four-year-old children performed better when a definite article was used (94\%) than when an indefinite article was used (76\%). Van Hout, de Ree and de Ree (2008) and van Hout et al. (2010) used truth-value-judgment tasks. In the study by van Hout et al. (2008) the participants (Dutch-speaking-children aged 4;1 to 5;4) had to accept ("yes") or reject ("no") sentences presented orally describing a picture. The participants accepted sentences in which the indefinite article referred to a new referent in a picture in only $58 \%$ of the cases; they allowed the indefinite article to refer to a given referent to the considerable proportion of $88 \%$ and, consequently, interpreted it as an existential quantifier. The definite article was clearly associated with given 
referents (96\%) and not with new ones (only 30\% acceptance). Hence, the children showed substantial difficulty to recognize that an indefinite article is used to refer to a new referent. In order to test whether participants understand that an indefinite article refers to a new referent, while it is not possible to refer to a new referent with a definite article, a truth-value-judgment task was constructed by van Hout et al. (2010, experiment 1). In this task, a picture was presented on the left side depicting a man giving a balloon to his baby in a pram next to him; on the right side of the picture, there was a man with many balloons in his hand. This picture was accompanied by the sentence "The dad gave the baby a balloon". Then, a second picture was presented in which one of the balloons of the man on the right side was flying away: that is, a balloon that has not been introduced in the sentence before. The corresponding question was either 1.) "Did a balloon fly away?" (correct answer: yes) or, 2.) "Did the balloon fly away?" (correct answer: no). The adult control group answered the first question correctly in $92 \%$ of the time and mostly negated the second question (only, 21\% "yes"-responses). In contrast, most of the children (aged 3;1 to 5;8) predominantly answered both questions with "yes" and, in this way, erroneously accepted that definite articles were used to refer to new objects. The children hence did not distinguish between indefinite and definite articles with respect to new referents. The task also addressed the comprehension of definite articles. For example, a picture was presented with a boy holding a kite on the left side and a fence with a kite on the right side. In the corresponding sentence, the boy's kite was introduced: "A boy was flying his kite." In the second picture, the boy's kite - that is, the referent, already mentioned - was flying away. The test question was either "Did a kite fly away?" (correct answer: yes? [the authors were not sure about the participants' responses]) or "Did the kite fly away?" (correct answer: yes). Both children and adults predominantly answered both questions with "yes" in this condition, showing that the participants accepted that both definite and indefinite articles could be used to refer to given referents, the latter obviously in the sense of an existential quantifier. Van Hout et al. (2010, experiment, 2) conducted another comprehension task using the "referent-selection paradigm": the child's task was to listen to a short story told by the experimenter and to move one referent in a picture in order to make the picture compatible with the content of the story. The referents were attached to the picture with Velcro and could be picked up and moved. Children aged 3;7 to 5;3 mostly interpreted the definite article correctly (87\%; adults: $96 \%)$. However, with respect to the interpretation of indefinite articles, only the adults chose more or less consistently (87\%) the new referent, whereas the children did this only $41 \%$ of the time.

The pattern 'new better than given' was mostly found in production studies in which participants had to respond to questions: children aged $3 ; 6$ to $5 ; 5$, who participated in Schafer and de Villiers' (2000) study, used the indefinite article correctly between $86 \%$ and $97 \%$ of the time and the definite article only between $47 \%$ and $70 \%$. Roth (2016) investigated the encoding of new and given referents by German-speaking children between the ages of $3 ; 11$ and $4 ; 11$ and adults with a similar method as Schafer and de Villiers (2010). The children performed better in the indefinite condition (91\%) than in the definite condition (53\%). Chailleux (2017) also applied the method used by Schafer and de Villiers (2000) to test the production of different types of indefinite and definite articles by French-speaking children between the ages of three and five years and adults. The children had more difficulties with the correct marking of given referents (between $50 \%$ and $74 \%$ correct) than of new referents (between $92 \%$ and $99 \%$ correct). Concerning the use of definite articles, the children performed better with increasing age. The studies reported so far, who found the 
pattern 'new better than given', asked their participants to respond to questions. Another method was applied in a study by de Cat (2011) in which French-speaking children aged $2 ; 6$ to $5 ; 5$ had to narrate a picture story. The use of indefinite articles for new referents was relatively high in every group, ranging from $83 \%$ to $95 \%$. The proportion of definite expressions (including pronouns) for referring to referents that have already been mentioned in the story but were new in a picture (story-old, picture-new) ranged from $50 \%$ to $83 \%$, whereas referents that were story-old and picture-old were verbalised consistently with definite expressions $100 \%$ of the time. In comprehension, the only study that found the pattern 'new better than given' is the one by Karmiloff-Smith (1979) in which French-speaking children from the ages of $3 ; 9$ to $10 ; 10$ had to act out stories. Concerning given referents, children improved with increasing age.

Some studies did not find an obvious pattern ('new as good as given'): the German-speaking participants' task in another experiment in Roth (2016) was to answer a hand-puppet's questions about pictures and video scenes presented on a computer screen only visible for the participant. The design was similar to the one used by Schaeffer and Matthewson (2005), except that Roth (2016) ensured that the referents were not present in the shared visual context. The children as well as the adults used articles for new and given referents appropriately in more than $90 \%$. In addition to the story completion task described above, Chailleux (2017) also conducted an experiment similar to Schaeffer and Matthewson's (2005) study with visual support. Children as well as adults reached high accuracy scores (more than 90\%) when referring to new and given referents. Keydeniers, Eliazer and Schaeffer (2017) asked Dutch-speaking participants questions about pictures and scenes. The correct use of indefinite and definite articles rose with increasing age; overall, there are no significant differences between the percentages of correctly used indefinite and definite articles. Table 3 summarizes the patterns found in production and comprehension studies.

Some further studies do not allow to draw a comparison of new and given referents since the investigated new referents were not really hearer-new. However, they investigated the acquisition of definite articles serving as markers of given referents: Maratsos $(1974,1976)$ asked children between $3 ; 0$ and $4 ; 5$ to respond to questions. The three-year-olds performed correctly in 55\% and the four-year-olds in more than $90 \%$ of the cases. In a story completion task, Karmiloff-Smith (1979) used Maratsos' design in order to test French-speaking children between the ages of $3 ; 3$ and 11;1. The youngest age group performed correctly in only $40 \%$ of the cases; with increasing age, the proportion of correctly used definite articles rose and the oldest age group used them correctly in $100 \%$ of the cases. Van Hout et al. (2010) also asked their participants to answer questions in order to elicit markers of given referents and found that children between the ages of $3 ; 1$ and $5 ; 8$ produced the article the correctly in $64 \%$ of the cases. In their second experiment, van Hout et al. (2010) combined the sentence completion task with a production task (description of pictures). The proportion of correctly produced definite articles serving as markers of given referents amounted to $66 \%$ for children aged $3 ; 7$ to $5 ; 3$. Compared to the purely verbal task in the authors' first experiment, the proportion of correctly produced definite articles rose slightly in the second experiment (by 2\%). Van Hout et al.'s first experiment was replicated by Keydeniers et al. (2017): the participants showed substantial difficulty to produce definite articles (19\% correct use of definite articles in children aged $2 ; 3$ to $3 ; 7$ and up to $64 \%$ in children aged $8 ; 0$ to $8 ; 4$ ). In a 
sentence completion task, children's performance ranged from $0 \%$ to $71 \%$ (Zehler and Brewer 1982). Very few mistakes were committed by the participants in Schaeffer and Matthewson's (2005) study. In the definite-eliciting context, the proportion of erroneously used indefinite articles amounts to only $2 \%$ for children between, $2 ; 1$ and adults.

\section{Summary and consequences for the present study}

To sum up, the results obtained in previous studies on the acquisition of indefinite and definite articles serving as markers of givenness show considerable heterogeneity. Concerning production, the pattern 'given better than new' emerged predominantly in studies in which participants described pictures, whereas the opposite pattern 'new better than given' tends to appear in studies with purely verbal tasks. An exception is de Cat's (2011) study: despite the visual support, the participants showed the pattern 'new better than given'. In three production studies (Roth, 2016; Chailleux, 2017; Keydeniers et al., 2017), no clear pattern was found; talking about given referents seemed to be mastered as well as talking about new referents. However, in these three studies the participants only had to produce single sentences and not longer, coherent text sequences. With respect to comprehension, only Karmiloff-Smith (1979) found the pattern 'new better than given'. Results from studies explicitly comparing tasks with visual support and purely verbal tasks suggest that experiments with visual support are better suited to elicit indefinite and definite articles serving as markers of givenness.

The methods used so far for investigating production and comprehension of indefinite and definite articles have several advantages and disadvantages. For production, previous studies have shown that methods with visual support were more successful to elicit the target structures than purely verbal tasks. Therefore, a picture story was used in the present study. This method is particularly appropriate because participants are prompted to produce natural text sequences and not just single sentences or even noun phrases. However, previous studies did not make sure that only definite articles (and not pronouns) are allowed when verbalizing given referents. Based on the picture story used by de Cat (2011), we developed a similar picture story in which only noun phrases with definite articles can be used to refer to given referents. As regards comprehension, the truth-value-judgment task is a well-established and reliable method in language acquisition research. Therefore, we adapted the truth-value-judgment task developed by van Hout et al. (2010) for the purpose of the present study.

\section{Research questions}

The present study seeks to investigate the production and comprehension of indefinite and definite articles as markers of givenness by German-speaking children. In contrast to several previous studies in which children merely had to refer to a single referent either new or given by producing single sentences, the participants in the present study had to produce longer text sequences in order to describe a picture story with new and given referents being present at the same time. Therefore, we considered the age span from four to seven years as being most relevant. The present study attempts to find answers to the following questions:

1.) Production: How does the ability of typically developing German-speaking children to encode the givenness status of referents (new versus given) with 
indefinite or definite articles develop? Does children's performance change with age and does it differ from adults' performance?

2.) Comprehension: How does the ability of typically developing German-speaking children to understand indefinite and definite articles as markers of the givenness status of referents (new versus given) develop? Does children's performance change with age and does it differ from adults' performance?

As previous studies on the acquisition of articles as markers of givenness have shown that children perform better with increasing age, we expect that children's performance will increase with age and that performance in earlier stages will differ from the adults' level.

3.) With regard to the ability to refer to given and new referents by means of definite and indefinite articles, it is unclear whether one reference type is acquired earlier or mastered more easily than the other. This might be influenced by different factors such as the developmental sequence of article forms and the complexity of the mapping between article form and givenness status. As presented above, there is some evidence that indefinite articles are produced earlier than definite articles in children's spontaneous speech. However, the denotation of a certain givenness status is ambiguous for indefinite articles, since they prototypically refer to new referents, but they can also denote given referents when used as an existential quantifier. On the other hand, definite articles appear more frequently in the input than indefinite ones, increasing their perceptibility. It is for this controversy between developmental sequence, ambiguity and frequency that we cannot predict which givenness status will be mastered better than the other.

\section{Participants}

In total, 93 typically developing German-speaking children and 20 adults participated in the study. The children were recruited in daycare centres as well as in two primary schools in Bonn, a city located in the German state of North Rhine-Westphalia. Parents were given written information about the study as well as a questionnaire about their child's developmental history. Children with a reported developmental disorder were excluded from the study. All parents gave their written consent for the participation of their children in the present study. The study was approved by the ethic committee of the German Society for Linguistics (Deutsche Gesellschaft für Sprachwissenschaft).

Nonverbal cognitive abilities were tested with the German version of the CPM (Coloured Progressive Matrices; Bulheller \& Häcker, 2006). Only children with nonverbal abilities in the normal range were included in the study. Children whose performance was below the $25^{\text {th }}$ percentile were excluded (two five-year-olds and three seven-year-olds). Monolingual as well as bilingual children were included, as long as they performed within the normal range in a language test battery that assessed relevant aspects of formal language skills in German (see Table 4) with age-appropriate standardized tests. As will be outlined in the results sections, the bilingual children did not differ significantly from the monolingual children with respect to their performance in the production and comprehension experiments. We therefore decided to include bilingual children with age-appropriate knowledge of German in the sample. With $22 \%$ of bilingual children, the sample reflects the population from which it is drawn: in 2016, 38\% of the children younger than 6 
years and $37 \%$ of the children aged six to ten years had a migrant background in Germany. ${ }^{1}$

Based on the results of the test battery presented in Table 4, only children with age-appropriate language skills were included in this study. Monolingual or bilingual children whose $\mathrm{t}$-scores were 40 or higher in the tests were included as they represent clear cases of age-appropriate language skills. If a child scored between 36 and 40 in only one test of the test battery, he or she was also included in the study. Table 5 shows the performance of the children with typical language development in the standardized language tests.

The 20 adults included in the study were students from the Department of German Studies and Arts of the Philipps-University Marburg in the German state Hesse aged 20 to 27 years (mean age: $\approx 24.6$ years; $\mathrm{SD} \approx 1.3$ ). The condition for participation was that their first language was German. The adult participants gave their written consent and received written information about the study. The adult group was included to investigate differences in the performances between children and adults.

\section{Study 1: Elicited production \\ Method}

\section{Design and materials}

The material consists of two picture stories of six pictures each, oriented towards the picture story developed by de Cat (2011, p. 840). The children were asked to describe the pictures in succession. The pictures show animals who are entering a tree or a carriage. The animals in the first story have to be labelled with masculine nouns, while the second story required the use of feminine nouns. Therefore, the participants do not have the possibility to use pronouns, but are obliged to renominalize. All nouns (animal names) are acquired before the age of 4;0 according to a German database of norms for age of acquisition (Schröder, Gemballa, Ruppin \& Wartenburger, 2012).

Story 1 (masculine nouns, see Figure 1):

Picture 1: A bird is sitting next to a tree.

Picture 2: The bird is sitting in the tree and a monkey is standing next to it.

Picture 3: The monkey is sitting in the tree as well and a beetle is standing next to it.

Picture 4: The beetle is also sitting in the tree and a tiger is standing behind it.

Picture 5: The tiger is sitting in the tree as well and a rabbit is standing next to it.

Picture 6: The rabbit is also sitting in the tree. The animals are too heavy, and the crown of the tree is collapsing.

Story 2 (feminine nouns):

Picture 1: There is a horse in front of a carriage. A cat is coming.

Picture 2: The cat is also sitting in the carriage and a mouse is coming.

Picture 3: The mouse is also sitting in the carriage and a duck is coming.

Picture 4: The duck is also sitting in the carriage and a cow is coming.

Picture 5: The cow is also sitting in the carriage and a giraffe is coming.

Picture 6: The giraffe is also sitting in the carriage and it collapses because of the weight of all the animals.

\footnotetext{
${ }^{1}$ Source: Autorengruppe Bildungsberichterstattung. 2018. Bildung in Deutschland 2018. Ein indikatorengestützter Bericht mit einer Analyse zu Wirkungen und Erträgen von Bildung. Retrieved from < https://www.bildungsbericht.de/de/bildungsberichte-seit-2006/bildungsbericht-2018/pdf-bildungsbericht2018/bildungsbericht-2018.pdf >.
} 
Table 4. test battery for the assessment of language skills

\begin{tabular}{llll}
\hline language domain & \multicolumn{1}{c}{$\begin{array}{c}\text { age groups in this } \\
\text { study }\end{array}$} & instrument & authors and years of publication \\
\hline $\begin{array}{c}\text { receptive } \\
\text { vocabulary }\end{array}$ & $4-7$ & $\begin{array}{c}\text { PPVT-4 } \\
\text { Word-picture-matching task }\end{array}$ & $\begin{array}{c}\text { German adaption by Lenhard, Segerer, Lenhard } \\
\text { \& Suggate, 2015 }\end{array}$ \\
\hline $\begin{array}{c}\text { productive } \\
\text { vocabulary }\end{array}$ & 4 & $\begin{array}{c}\text { PDSS: subtest 5 (production of nouns) und subtest 6 } \\
\text { (production of verbs) }\end{array}$ & Kauschke \& Siegmüller, 2010 \\
\cline { 2 - 4 } & $5-7$ & SET 5-10: subtest 1 (picture naming) & Petermann, 2012 \\
\hline $\begin{array}{c}\text { receptive } \\
\text { grammar }\end{array}$ & $4-7$ & $\begin{array}{c}\text { TSVK short version/screening } \\
\text { Sentence comprehension task }\end{array}$ & Siegmüller, Kauschke, Minnen \& Bittner, 2011 \\
\hline $\begin{array}{c}\text { productive } \\
\text { grammar }\end{array}$ & 4 & SETK 3-5: subtest memorizing of sentences & Grimm, 2001 \\
\cline { 2 - 4 } & $5-7$ & SET 5-10: subtest 7, production of sentences & Petermann, 2012 \\
\hline
\end{tabular}


Table 5. description of the sample and mean values (rounded, with rounded standard deviations in brackets) of t-scores and percentiles (CPM)

\begin{tabular}{|c|c|c|c|c|c|c|c|c|c|c|}
\hline $\begin{array}{l}\text { age } \\
\text { group }\end{array}$ & $\mathrm{n}$ & $\begin{array}{l}\text { monolingual } \\
\text { (m)/bilingual } \\
\text { (b) }\end{array}$ & $\begin{array}{l}\text { mean age } \\
\text { in months } \\
\text { (SD); } \\
\text { age range }\end{array}$ & $\begin{array}{l}\text { Word } \\
\text { comprehension } \\
\text { (PPVT-4) }\end{array}$ & $\begin{array}{c}\text { memorizing of } \\
\text { sentences (SETK)/ } \\
\text { sentence } \\
\text { production (SET) }\end{array}$ & $\begin{array}{c}\text { Sentence } \\
\text { comprehension } \\
\text { (TSVK) }\end{array}$ & $\begin{array}{c}\text { picture } \\
\text { naming } \\
\text { (SET) }\end{array}$ & $\begin{array}{c}\text { object } \\
\text { naming } \\
\text { (PDSS } \\
\text { nouns) }\end{array}$ & $\begin{array}{l}\text { action } \\
\text { naming } \\
\text { (PDSS } \\
\text { verbs) }\end{array}$ & CPM \\
\hline 4 & 20 & m: 19; b: 1 & $\begin{array}{r}53.5(3.5) \\
4 ; 1-4 ; 11\end{array}$ & $55.4(6.5)$ & $57.6(8.4)$ & $72.8(17.6)$ & - & $52.0(3.3)$ & $57.5(9.6)$ & $77.4(16.3)$ \\
\hline 5 & 28 & m: 24; b: 4 & $\begin{array}{r}64,1(2.8) \\
5 ; 0-5 ; 10\end{array}$ & $57.9(7.0)$ & $61.3(7.7)$ & $65.7(10.4)$ & $62.8(10.2)$ & - & - & $73.4(18.0)$ \\
\hline 6 & 20 & m: 16; b: 4 & $\begin{array}{r}79,2(2.8) \\
6 ; 4-6 ; 11\end{array}$ & $55.6(8.6)$ & $59.5(14.9)$ & $55.7(11.2)$ & $56.4(10.6)$ & - & - & $69.6(21.6)$ \\
\hline 7 & 25 & m: 12; b: 13 & $\begin{array}{c}89.7(2.9) \\
7 ; 1-7 ; 11\end{array}$ & $52.7(8.8)$ & $66.3(14.0)$ & $54.3(12.0)$ & $52.1(10.5)$ & - & - & $65.6(22.4)$ \\
\hline
\end{tabular}



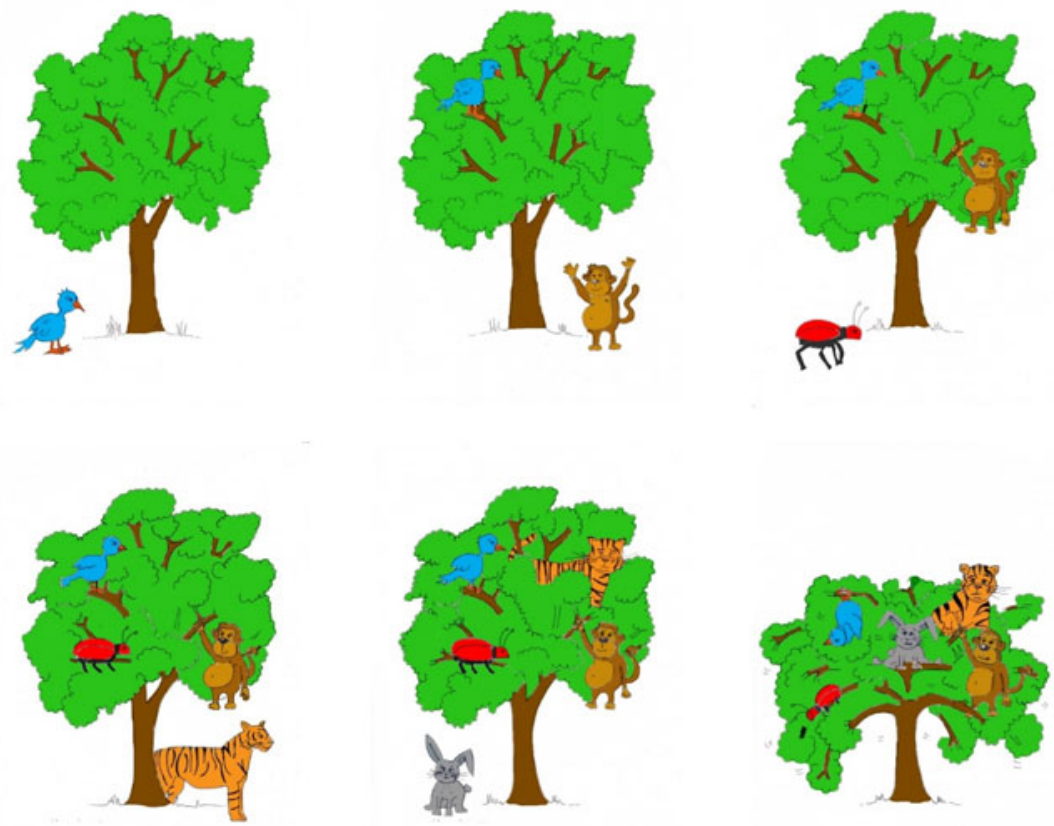

Figure 1. example of picture story (story 1 )

Ten new referents and eight given referents were elicited per participant. The final picture of each story served as a meaningful end of the story.

The pictures were presented with PowerPoint ${ }^{\circledast}$ on a laptop screen. The laptop (Dell Inspiron 15) with a 15.6-inch screen size was placed in front of the participant so that the participant could see the presentation, but the experimenter saw only the back of the laptop. A German version of the following instruction, recorded in a sound-proof booth of the phonetic laboratory of the University of Marburg, was presented:

"You are going to see two picture stories. Your task is to tell these two picture stories to [experimenter's name]. Don't forget that [experimenter's name] doesn't know the stories and that she can't see the pictures. Therefore, you should tell the stories very well so that ["experimenter's name"] can understand everything. It's important that you do not only describe the pictures, but that you tell two coherent stories. Here we go!"

This instruction was read out by a female voice to make the child think that the experimenter was indeed ignorant and hadn't ever seen the pictures or heard the stories before. The experimenter switched to the next picture of the story as soon as the participant had finished the description of a picture.

\section{Procedure}

All participants were tested individually. The data collection with the children took place in a quiet room in the daycare centre or primary school. Two test sessions were conducted: in the first session, the test battery was administered to assess the children's language skills. In the second session, taking place on another day, the two experiments (production and comprehension) as well as the CPM were conducted. At the end of the second section, every child received a present. The adults were 
Table 6. number of participants applying the 'strategy-types'

\begin{tabular}{lcccc}
\hline age group & variation in article use & bias indefinite & bias definite & bias "no article" \\
\hline 4 & 16 & 3 & - & 1 \\
\hline 5 & 22 & 5 & 1 & - \\
\hline 6 & 15 & 3 & 2 & - \\
\hline 7 & 24 & - & 1 & - \\
\hline adults & 20 & - & - & - \\
\hline$\sum$ & 97 & 11 & 4 & 1 \\
\hline
\end{tabular}

tested in a quiet room of the University of Marburg and only participated in the production and comprehension experiment.

The participants' utterances were recorded on a digital dictation recorder and additionally noted on a prepared protocol during the test session.

\section{Results}

Strategies for the encoding of new and given referents

Initial analyses of the data showed that some children applied a kind of 'strategy' when verbalizing new or given referents: some children tended to use only indefinite articles, irrespective of the givenness status of the referent. Other children in turn tended to use only definite articles. Against this background, the following 'strategy-types' were defined:

- indefinite bias: participants who predominantly use the indefinite article and the definite article not more than once

- definite bias: participants who predominantly use the definite article and the indefinite article not more than once

- "no article" bias: participants who don't use articles with only a single exception

- "variation in article use": all the other participants

Table 6 shows the distribution of the participants to the 'strategy-types'.

Participants with clear biases were excluded from the statistical analyses, because they would have distorted the mean values: participants with the bias "indefinite articles" verbalize all new referents correctly, but, consequently, all given referents incorrectly; participants with the bias "definite articles" in turn verbalize all given referents correctly, but new referents incorrectly; and participants with the bias "no articles" do not produce the linguistic structures of interest at all. Therefore, only the data from the 97 participants (77 children and all adults) showing variation in article use were considered in the following statistical analyses.

\section{Reference to new referents}

The referring expressions for the ten new referents were assigned to one of the following categories.

- noun phrase with indefinite article (correct)

- noun phrase with definite article (false) 


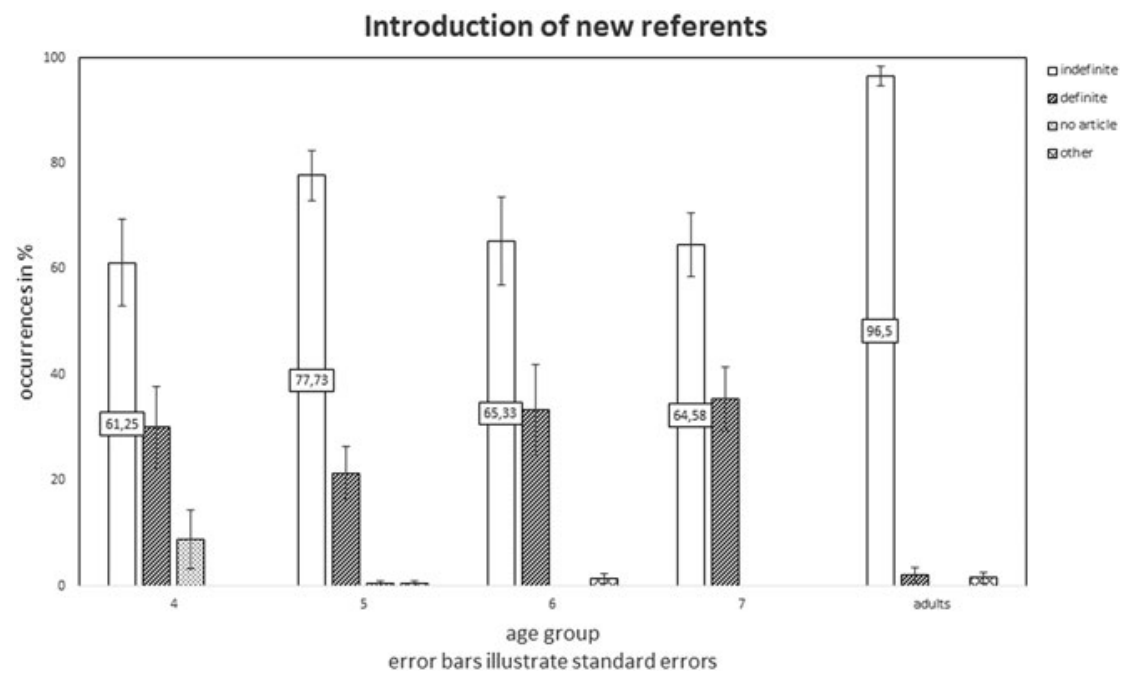

Figure 2. Proportions of forms introducing new referents

- noun without article (false)

- other (for example "something like a tiger")

The percentages of noun phrases of each category relative to the total number of referents realized was calculated. Figure 2 illustrates how the participants encode new referents in each of the age groups; the corresponding descriptive statistics are given in Table 7.

Accuracy scores of noun phrase realization were then compared between age groups. Since the data did not obey normal distribution, nonparametric Kruskal-Wallis tests were performed. The results showed that the effect of age was significant concerning the use of correct indefinite articles (chi-square $(4)=23.588 ; \mathrm{p}=0.000$ ), definite articles (chi-square $(4)=23.105 ; \mathrm{p}=0.000$ ) and nouns without articles (chi-square(4) $=21.262 ; \mathrm{p}=0.000$ ). Dunn-Bonferroni post-hoc tests showed which groups differed significantly from each other (see Table 8 ).

In addition to the group comparisons, a correlation analysis for the variables "age in months" and "percentages of correct reactions" was conducted. Since the underlying hypothesis is that children perform the better the older they are, a one-tailed test was applied. No significant correlations were found $\left(r_{s}=-0.006 ; p=0.479\right)$.

\section{Reference to given referents}

The referring expressions for the eight given referents per participant were assigned to one of the following six categories:

- noun phrase with definite article (correct)

- demonstrative pronoun (correct)

- pronoun (correct, but not the best option because of unclear references)

- noun phrase with indefinite article (false) 
Table 7. Descriptive statistics (introduction of new referents) ${ }^{2}$

\begin{tabular}{|c|c|c|c|c|c|c|}
\hline & & 4 & 5 & 6 & 7 & adults \\
\hline \multirow[t]{2}{*}{ indefinite } & mean in $\%$ & 61.25 & 77.73 & 65.33 & 64.58 & 96.50 \\
\hline & SD & 33.04 & 22.66 & 80.00 & 29.19 & 8.13 \\
\hline \multirow[t]{2}{*}{ definite } & mean in \% & 30.00 & 21.36 & 33.33 & 35.42 & 2.00 \\
\hline & SD & 30.98 & 23.36 & 33.09 & 29.19 & 6.96 \\
\hline \multirow[t]{2}{*}{ no article } & mean in $\%$ & 8.75 & 0.45 & - & - & - \\
\hline & SD & 22.47 & 2.13 & - & - & - \\
\hline \multirow[t]{2}{*}{ other } & mean in \% & - & 0.45 & 1.33 & - & 1.5 \\
\hline & SD & - & 2.13 & 3.52 & - & 4.89 \\
\hline
\end{tabular}

Table 8. significant group differences (introduction of new referents)

\begin{tabular}{|c|c|c|c|c|}
\hline & significant group differences & z & $\mathrm{p}$ & $\approx r$ \\
\hline \multirow{4}{*}{ 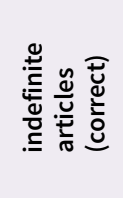 } & 4-year-olds vs. adults & -4.044 & 0.001 & 0.67 \\
\hline & 5-year-olds vs. adults & -3.146 & 0.017 & 0.49 \\
\hline & 6-year-olds vs. adults & -3.641 & 0.003 & 0.62 \\
\hline & 7-year-olds vs. adults & -3.994 & 0.001 & 0.60 \\
\hline \multirow{4}{*}{ 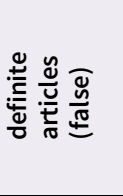 } & 4-year-olds vs. adults & 3.445 & 0.006 & 0.57 \\
\hline & 5-year-olds vs. adults & 3.295 & 0.010 & 0.51 \\
\hline & 6-year-olds vs. adults & 3.768 & 0.002 & 0.64 \\
\hline & 7-year-olds vs. adults & 4.284 & 0.000 & 0.65 \\
\hline \multirow{4}{*}{ 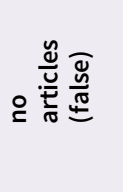 } & 4-year-olds vs. adults & 3.862 & 0.001 & 0.64 \\
\hline & 4-year-olds vs. 6-year-olds & 3.604 & 0.003 & 0.65 \\
\hline & 4-year-olds vs. 7-year-olds & 4.013 & 0.001 & 0.63 \\
\hline & 4-year-olds vs. 5-year-olds & 3.383 & 0.007 & 0.55 \\
\hline
\end{tabular}

- noun without article (false)

- other

Figure 3 illustrates the results for the encoding of given referents by the different age groups; the relevant descriptive statistics are given in Table 9.

\footnotetext{
${ }^{2}$ We have also calculated and compared the arithmetic means for monolingual and bilingual children within each age group with respect to the percentage of correctly used indefinite articles - with the result that these means did not differ substantially from each other. In addition, no group differences emerged when comparing all monolingual children with all bilingual children with respect to the correct use of indefinite articles $(U=512.000 ; p=0.641)$. The group of the seven-year-old children comprised ten bilingual participants whose native languages don't have articles (Russian, Serbo-Croat, Turkish, Slovak). In an additional analysis, we excluded these ten children in order to verify that the structure of the native language did not influence performance. We found that the arithmetic mean of correctly used indefinite articles was even smaller without the ten participants in question $(59,29 \%)$ and that the observed significant group differences for indefinite articles in Table 8 remained unchanged.
} 


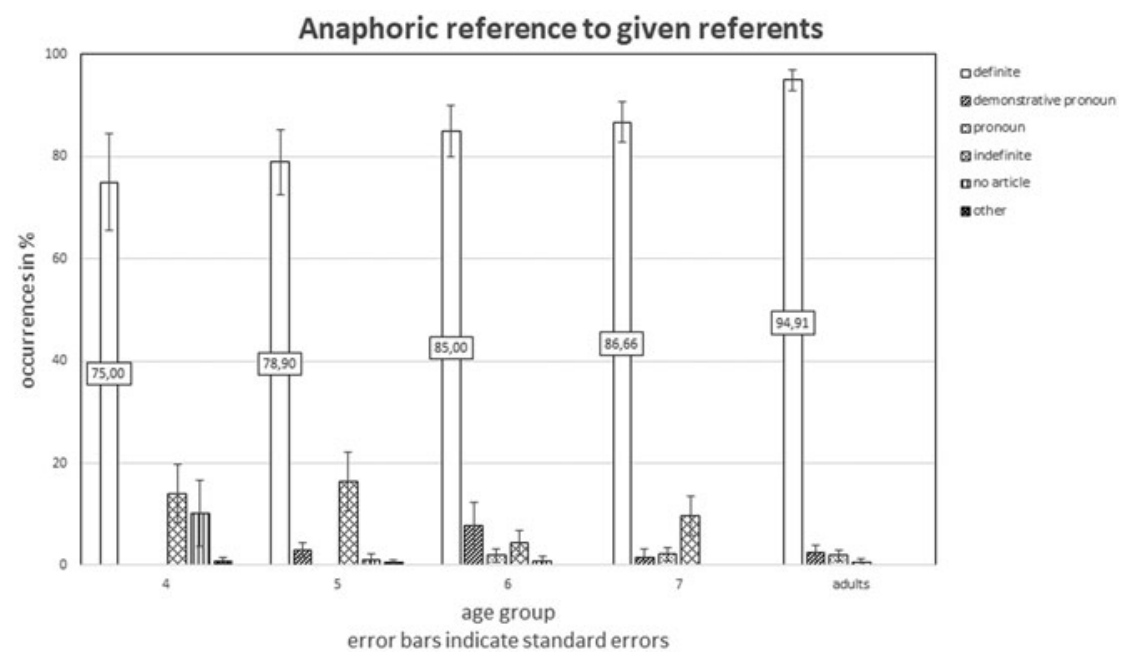

Figure 3. Proportions of forms referring to given referents

Table 9. Descriptive statistics (reference to given referents) ${ }^{3}$

\begin{tabular}{llccccc}
\hline \multirow{2}{*}{ definite } & & \multicolumn{1}{c}{4} & 5 & 6 & 7 & adults \\
\cline { 2 - 7 } & mean in \% & 75.00 & 78.90 & 85.00 & 86.66 & 94.91 \\
\cline { 2 - 7 } demonstrative pronoun & SD & 37.91 & 29.71 & 19.28 & 19.44 & 8.60 \\
\cline { 2 - 7 } & mean in \% & 2.92 & 2.92 & 7.78 & 1.56 & 2.50 \\
\cline { 2 - 7 } pronoun & SD & 6.74 & 6.74 & 17.67 & 7.65 & 6.54 \\
\hline \multirow{2}{*}{ indefinite } & mean in \% & - & - & 1.94 & 2.16 & 1.96 \\
\cline { 2 - 7 } & SD $\approx$ & - & - & 5.19 & 6.16 & 4.81 \\
\hline \multirow{2}{*}{ no article } & mean in \% & 14.06 & 16.48 & 4.44 & 9.62 & 0.63 \\
\cline { 2 - 7 } & SD & 22.76 & 26.83 & 9.38 & 18.59 & 2.80 \\
\hline \multirow{2}{*}{ other } & mean in \% & 10.16 & 1.14 & 0.83 & - & - \\
\cline { 2 - 7 } & SD & 25.50 & 5.33 & 3.28 & - & - \\
\hline & mean in \% & 0.78 & 0.57 & - & - & - \\
\cline { 2 - 7 } & SD & 3.13 & 2.67 & - & - & - \\
\hline
\end{tabular}

\footnotetext{
${ }^{3}$ Again, the arithmetic means of percentages of correctly used definite articles by monolingual and bilingual children within each age group did not differ substantially from each other. Moreover, there were no significant group differences between all monolingual and bilingual children $(U=489.000 ; p=$ 0.431). Again, we excluded the ten participants with native languages without articles from the analyses and found that the arithmetic mean was reduced marginally $(80,06 \%)$; but the absence of significant group differences was confirmed.
} 
Kruskal-Wallis-tests showed that there were no group differences apart from the use of nouns without articles (chi-square $(4)=12.812 ; \mathrm{p}=0.012$ ). In addition, there was no significant correlation between children's age in month and the number of correct responses $\left(r_{s}=0.104 ; \mathrm{p}=0.184\right)$.

\section{Discussion of experiment 1}

The production experiment investigated how children aged four to seven years in comparison to adults use indefinite and definite articles as markers for the givenness of referents in an elicited production task.

With regard to the use of indefinite articles to introduce new referents, adults used on average $96.5 \%$ of indefinite articles correctly. None of the child groups reached this accuracy level, suggesting that the capacity to adequately mark new referents is not fully acquired by the age of seven. As indicated by the absence of group differences and correlations with age, there seems to be no clear developmental progression in the way children encoded new referents. The dominant error type was the use of a definite article instead of an indefinite one (labelled egocentric errors by Maratsos, 1974, 1976).

Concerning the anaphoric use of definite articles to mark given referents, the adults' percentage of definite article use amounts up to $94.1 \%$. Even though the percentages of correct definite articles rose gradually with age (from $75 \%$ to $87 \%$ ), there were no significant differences between the age groups. If mistakes were made when referring to a given referent, a definite article was most often replaced by an indefinite article (so-called Discourse INTEGRATION ERRORS; de Cat, 2011).

In summary, the results suggest that the children perform better in marking given referents than new ones: whereas there were significant group differences between the child groups and the adults for the marking of new referents, no such differences were observed for the marking of given referents. This suggests the existence of a pattern 'given better than new' in production, confirming findings of previous studies using similar methods (Warden, 1976, experiment 3; Emslie \& Stevenson, 1981, experiment 3; Power \& dal Martello, 1986, experiment 1). In contrast, no differences between the production of indefinite and definite articles serving as markers of givenness emerged in studies conducted by Roth (2016), Chailleux (2017) and Keydeniers et al. (2017). In these studies, participants only had to produce single sentences with one reference type (given or new). In the present production experiment, however, the participants had to verbalize whole picture stories including several new and given referents. This task difference might account for the diverging results. The opposite pattern 'new better than given' was only found by de Cat (2011), whose study design has been adopted in the present study. The differing results between de Cat's (2011) and the present study might be due to the different languages involved and the respective language-specific encodings of information structure. De Cat (2011, p. 841) points out: "What makes spoken French special is that, when the new referent is encoded as a subject, a presentational structure (il y a $x$ 'there is $\mathrm{x}^{\prime}$ ) [...] is strongly preferred (at least in informal speech) over the canonical SV option". Therefore, the French-speaking children might have fewer problems with the encoding of new referents than the German-speaking children.

The main error type found in the production study was the use of definite instead of indefinite articles for new referents. The example in (4), the description of the first 
picture story by a seven-year old monolingual girl, illustrates the pattern 'given better than new' (egocentric errors marked in bold):

(4) Da ist ein Baum und der Vogel möchte sich auf den Baum setzen. Der Vogel sitzt auf dem Baum und der Affe ruft ihn runter. Der Affe holt den Vogel runter und da kommt ein Käfer. Der Käfer möchte dem Affen was sagen und der Löwe kommt vorbei. Der Löwe möchte dem Käfer was sagen. Der Hase kommt auch vorbei. Alle fünf sitzen aufm Baum und wollen was sagen. Der Baum hält die fünf Tiere nicht mehr aus.

[There is a tree and the bird would like to sit on the tree. The bird is sitting on the tree and the monkey calls him. The monkey takes the bird down and a beetle is coming. The beetle would like to say something to the monkey and the lion is coming along. The lion wants to say something to the beetle. The rabbit is also coming along. All five of them are sitting on the tree and want to say something. The tree cannot hold the five animals anymore.]

The example shows that even a child at school age with good narrative skills does not consistently use indefinite articles to mark new referents. In the literature, the following three accounts have been put forward in order to explain such egocentric errors:

1.) In contrast to adults, children lack the capacity to represent the interlocutor's perspective. Therefore, they are not able to recognize that information given for them might be new for their interlocutor. This explanation was proposed by Warden (1976) as well as by Schaeffer and Matthewson (2005); the latter suggested a lack of the Concept of Non-Shared Assumptions (CNSA), according to which "[s]peaker and hearer assumptions are always independent" (Schaeffer \& Matthewson, 2005, p. 69). Even though the authors do not explicitly use the term, it is obvious that the concept of theory of mind is relevant in this context. According to Premack and Woodruff (1978, p. 515), who coined the term, "[a]n individual has a theory of mind if he imputes mental states to himself and others". It is generally assumed that children younger than four years of age fail in so-called false-belief tests, used to assess whether a person has a theory of mind (Saracho, 2014, p. 955). Since the children participating in the present study were four years and older, they probably disposed of the necessary cognitive prerequisites to recognize that their interlocutors' perspectives differed from their own. However, the children's task in the present study might have been more complex than a false-belief test: for the adequate description of the pictures, it was not only necessary to recognize for new referents that there was a discrepancy between the own and the interlocutor's perspective; in addition, children had to activate their linguistic knowledge and encode referents according to their givenness status. Therefore, perspective-taking accounts might partly explain the results of the present study.

2.) Sims (1990) and de Cat (2011) assume that children are aware of the fact that the listener is not really ignorant, even though he or she might be blindfolded. Therefore, referents are not marked as new for the interlocutor. In the present study, however, the instruction was verbalized by another female's voice in order to make the children believe that the experimenter was ignorant; in addition, the female voice emphasized that the experimenter, who could not see the pictures, did not know the picture story and that, therefore, the pictures had to be 
described very well. Against this background, this explanation cannot account for the results of the present study.

3.) Van Hout et al. (2010) argue within the framework of bi-directional optimality theory adopting an account proposed by Hendriks, de Hoop, Krämer, de Swart and Zwarts (2010). According to their view, children, in contrast to adults, have not yet ranked two constraints guiding form-meaning associations. The two constraints in question are i) the association of definite articles with discourse referents with DETERMINED REFERENCE and ii) the principle of Referential Economy according to which a speaker prefers pronouns over definite articles and pronouns and definite articles over indefinite articles leading to a higher ban of indefinites expressed in the constraint AVOID INDEFINITES. In the adult ranking, DETERMINED REFERENCE is higher ranked than AVOID INDEFINITES. Consequently, the is the winner for determined referents, but violates the undominated DETERMINED REFERENCE when the referent is non-determined. The determiner $a$ does always violate the lower ranked constraint Avoid Indefinites, since indefinites are to be avoided in general, but produces the least severe violation in the context of new referents. The authors assume that children lacking the adult ranking of the two constraints arbitrarily choose one or the other article for the introduction of new referents. Applying the ranking Determined ReFERENCE $\gg$ Avoid Indefinites to the present study, it could be confirmed that some of the participants have not yet acquired the correct constraint ranking, resulting in the inconsistent use of articles for the introduction of new referents. However, the OT account proposed by van Hout et al. (2010) predicts consistent use of definite articles for given referents even if the relevant constraints are unranked. This is not compatible with our finding that children do not always use the definite article for given referents.

The second error type, the use of indefinite articles for given referents, emerged less frequently in our production study than egocentric errors. For these discourse integration errors de Cat (2011) assumes that the turning of pages renders it difficult for children to recognize that a referent has already been introduced in a previous picture. This assumption cannot explain the results of the present study: if the turning of pages led to discourse integration errors, these errors would probably occur consistently. A second explanation for discourse integration errors was put forward by Keydeniers et al. (2017) who observed indefinite article-overuse in their youngest age group $(2 ; 3$ to $3 ; 7)$. The authors apply van Hout et al.'s (2010) scalar implicature account for comprehension to production. The indefinite and definite article form a scale in which the latter is the stronger and more informative one. A hearer interpreting an indefinite article draws the implicature that the definite article would have been too strong and informative. As young children fail to recognize this scale, they do not anticipate the corresponding scalar implicature the interlocutor will draw when they produce an indefinite instead of a definite article. Given that even the youngest children committed discourse integration errors to a very small extent (14\%), the performance pattern cannot be explained on the basis of this scalar implicature account.

Since the pattern 'given better than new' was confirmed in our next study, we will introduce another possible explanation in the General Discussion. 


\section{Study 2: truth-value judgment task}

\section{Method}

\section{Design and materials}

The rationale behind the comprehension experiment follows van Hout et al. (2010) who tested the comprehension of indefinite and definite articles as markers of givenness with a truth-value judgment task. Similar to van Hout et al. (2010), pictures were presented to the participants, accompanied by a question that had to be answered with yes or no. In each picture, the zoo visitor Tom, who had been introduced during the practice phase, points at one of two animals of the same species. The animal names were controlled for length (two syllables) and age of acquisition (acquired until 4;0; database: Schröder et al., 2012). The task comprises the conditions new and given as well as distractors. In the following, each test condition and possible responses will be illustrated:

In the condition new, Tom points at an animal that is sitting still while the other animal is running away.

$\begin{gathered}\text { context sentence: } \\ \text { "Tom is pointing at a cat.” } \\ \text { (Tom zeigt auf eine Katze.") }\end{gathered}$
Figure 4. example picture of condition new (the German versions of
the stimuli are presented in brackets) $\begin{aligned} & \begin{array}{l}\text { cond questions: } \\ \text { condition 1: NEW } \\ \text { "Is a cat running away? } \\ \text { ("Läuft eine Katze weg?") } \\ \text { correct response: yes }\end{array} \\ & \text { "Is the cat running away?" } \\ & \text { ("Läuft die Katze weg?") } \\ & \text { correct response: no }\end{aligned}$

For example, in Figure 4, Tom is pointing at a cat that is sitting still while the other cat is running away. First, a descriptive context sentence is aurally presented: "Tom is pointing at a cat". With the relevant noun phrase, the speaker refers to the sitting yellow cat on the left side that is introduced into the discourse. Then, either the question "Is a cat running away?" $\left(\mathrm{NEW}_{\text {indef }}\right)$ or "Is the cat running away?" ( $\left.{ }^{\star} \mathrm{NEW}_{\mathrm{def}}\right)$ is presented aurally. If the test question comprises the indefinite noun phrase "a cat", the speaker refers to a new referent: that is, the cat on the right side of the picture that is running away; the correct answer is, consequently, "yes". This condition assesses whether the participant understands that the speaker refers to a new referent by using an indefinite noun phrase. In contrast, the question with the definite noun phrase "the cat" must be negated since the speaker refers anaphorically to the cat already introduced that is not running away. This condition tests whether the participant understands that it is not acceptable to refer to a new referent by a definite noun phrase. 
In the condition given, Tom points at an animal that is running away whereas the other animal is sitting still.

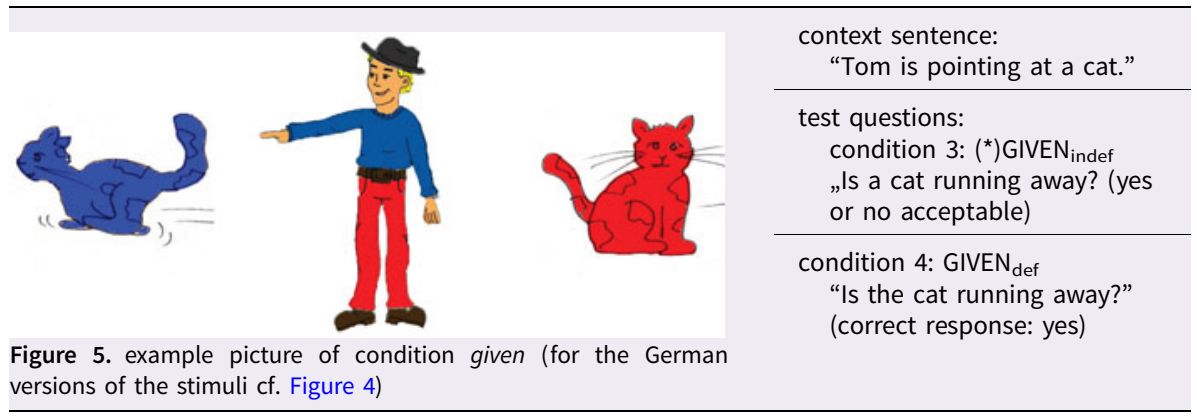

In Figure 5, Tom is pointing at a cat that is running away while the other cat is sitting still. With the noun phrase of the context sentence, the speaker refers to the running cat on the left side that is now introduced into the discourse. If the test question contains the indefinite noun phrase "a cat", the speaker is, strictly speaking, referring to a new referent; that is, the cat that is sitting. The correct answer from the perspective of information structure theory to this question would, therefore, be "no". But it is also acceptable to answer "yes" - in a logical sense, it is true that there is a cat that is running away. This question assesses the participant's tendency to apply indefinite articles to given referents in the sense of an existential quantifier. The correct answer to the question in condition $4\left(\mathrm{GIVEN}_{\mathrm{def}}\right)$ is "yes" because the speaker refers anaphorically to the already introduced cat that is in fact running away and tests whether the participant understands that the speaker normally refers to a given object by a definite noun phrase.

In the distractor condition, either both animals are running away or both animals are sitting still. In the case of both animals running away, the answer is always "yes", independently of the article used in the test question. If both animals are not moving, the answer is always "no", no matter which article is used in the test question. The condition DISTRACTOR was included to force children who might show a bias towards only yes- or no-answers to vary their answers.

To control for any confounding variables, the absolute size and the position of Tom and the animals were kept unchanged in every picture. Five colours (red, yellow, green, blue, brown) were used to colour the animals; the colours were changed systematically throughout the pictures. Tom's direction of pointing was also systematically varied.

Ten animals (bee, duck, owl, rabbit, camel, cat, lion, tiger, bird, zebra) were included in the comprehension experiment. Since every category was tested with two questions, 20 questions belonged to the condition new, 20 further questions to the condition given and 20 other questions served as distractors. Accordingly, the participants had to respond to 60 questions in total. To keep the motivation of the children alive, the experiment was interrupted shortly by two breaks: after the first 20 trials, the child was given a choice between a zebra figure or a rabbit figure and had to move it forward to a manger; after 20 further trials, the child was asked to move the chosen figure forward towards a watering place. And after the last 20 trials, the child finally had the opportunity to move the animal forward to the finishing line. 
The trials were presented in a pseudo-randomized order: each condition did not appear more than three times in a row and a picture never co-occurred with its differently coloured counterpart. In order to avoid sequence- and carry-over-effects, two lists were generated following the above-mentioned criteria and presented in two inverted orders so that four pseudo-randomized lists were available in total. The participants were assigned randomly to one of the lists.

The experiment was presented with the program PowerPoint ${ }^{\circ}$. At the beginning, a picture of Tom was shown, accompanied by the following instruction (this time verbalized by the experimenter herself):

"This man is called Tom. Tom is spending his day at the zoo. But the animals in the zoo have multiple colours. This surprises Tom, so he is pointing at the animals. Many animals are scared and run away from Tom. The computer will ask you a question about each picture, and your task is to answer the question with "yes" or "no". I'm going to show you what I mean. Here are some examples for you."

The instruction was followed by a familiarizing session.

The participants had as much time as they wanted to answer the test questions. When a new picture was presented, there was a silence of two seconds before the context sentence was audibly presented. Between the context sentence and the corresponding test question there was a silence of one second. All the sentences were read out by the same female trained speaker as in the production experiment; the sentences had also been recorded in a sound-proof booth of the phonetic laboratory of the University of Marburg.

The acoustic parameters duration, pitch and intensity of the test questions and the noun phrases in the test questions were measured with the program Praat ${ }^{\oplus}$ (Boersma \& Weenink, 2016). As Table 10 shows, a manipulation of the participants due to acoustic characteristics of the stimuli can be excluded.

\section{Procedure}

The data collection took place in the same rooms as the production study. The same laptop was used. The responses of the participants were noted down immediately on a prepared protocol.

\section{Results}

Statistical analyses: age group comparisons

Table 11 shows the mean proportions of correct responses for the four conditions for the age groups. ${ }^{4}$

\footnotetext{
${ }^{4}$ Mann-Whitney-U-tests revealed that monolingual and bilingual children did not differ significantly from each other with respect to the correct reactions in the four conditions (condition $1: \mathrm{U}=713.000$; $\mathrm{p}=0.527$; condition $2: \mathrm{U}=692.500 ; \mathrm{p}=0.353$; condition $3: \mathrm{U}=652.000 ; \mathrm{p}=0.197$; condition 4 : $\mathrm{U}=713.000 ; \mathrm{p}=0.493$ ). In addition, after having excluded the ten bilingual seven-year-old children with native languages without articles, neither the arithmetic means (condition 1: 55,33\%, condition 2 : 75,56\%, conditions 3 and 4: 92,67\%) nor the pairwise comparisons changed substantially. The only difference compared to the analyses including all the monolingual and bilingual children concerned condition 3: when the ten bilingual children in question were excluded, there were no longer significant differences between the 5-year-olds and the six-year-olds and between the four-year-olds and the seven-year-olds.
} 
Table 10. Acoustic parameters and statistical analyses

\begin{tabular}{|c|c|c|c|c|c|}
\hline acoustic parameter & & mean & $\mathrm{T}$ & df & sig. \\
\hline \multicolumn{6}{|l|}{ questions } \\
\hline \multirow[t]{2}{*}{ duration (sec.) } & with indefinite articles & 1.12 & 0.68 & 18 & 0.50 \\
\hline & with definite articles & 1.10 & & & \\
\hline \multirow[t]{2}{*}{ pitch $(\mathrm{Hz})$} & with indefinite articles & 216.32 & -1.22 & 18 & 0.24 \\
\hline & with definite articles & 219.16 & & & \\
\hline \multirow[t]{2}{*}{ intensity (dB) } & with indefinite articles & 60.53 & -1.23 & 18 & 0.24 \\
\hline & with definite articles & 60.93 & & & \\
\hline \multicolumn{6}{|l|}{ noun phrases } \\
\hline \multirow[t]{2}{*}{ duration (sec.) } & with indefinite articles & 0.56 & 1.12 & 18 & 0.28 \\
\hline & with definite articles & 0.52 & & & \\
\hline \multirow[t]{2}{*}{ pitch $(\mathrm{Hz})$} & with indefinite articles & 190.85 & -0.84 & 18 & 0.41 \\
\hline & with definite articles & 193.67 & & & \\
\hline \multirow[t]{2}{*}{ intensity (dB) } & with indefinite articles & 58.09 & -0.60 & 18 & 0.56 \\
\hline & with definite articles & 58.44 & & & \\
\hline
\end{tabular}

Table 11. mean proportions of correct responses in the comprehension experiment

\begin{tabular}{|c|c|c|c|c|c|c|}
\hline & & 4 & 5 & 6 & 7 & adults \\
\hline \multicolumn{7}{|c|}{ 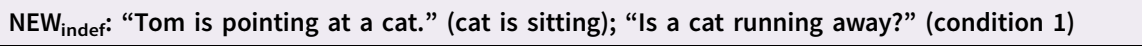 } \\
\hline \multirow[t]{2}{*}{ yes } & mean $\approx$ & $39.50 \%$ & $26.43 \%$ & $32.50 \%$ & $52.00 \%$ & $87.00 \%$ \\
\hline & $\mathrm{SD} \approx$ & 37.48 & 34.98 & 42.78 & 45.09 & 31.81 \\
\hline \multicolumn{7}{|c|}{ 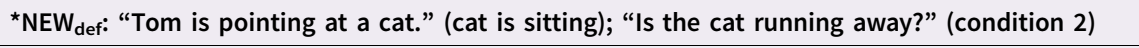 } \\
\hline \multirow[t]{2}{*}{ no } & mean $\approx$ & $70.00 \%$ & $78.57 \%$ & $85.56 \%$ & $77.33 \%$ & $98.33 \%$ \\
\hline & $\mathrm{SD} \approx$ & 38.84 & 34.73 & 32.06 & 40.38 & 7.45 \\
\hline \multicolumn{7}{|c|}{$\left({ }^{*}\right)$ GIVEN $_{\text {indef: }}$ "Tom is pointing at a cat." (cat is running); "Is a cat running away?" (condition 3 ) } \\
\hline \multirow[t]{2}{*}{ yes } & mean $\approx$ & $83.50 \%$ & $84.29 \%$ & $95.50 \%$ & $91.60 \%$ & $98.00 \%$ \\
\hline & $S D \approx$ & 17.25 & 20.63 & 11.46 & 22.30 & 6.16 \\
\hline \multicolumn{7}{|c|}{ GIVEN $_{\text {def: }}$ "Tom is pointing at a cat." (cat is running); "Is the cat running away?" (condition 4) } \\
\hline \multirow[t]{2}{*}{ yes } & mean $\approx$ & $83.00 \%$ & $82.86 \%$ & $94.50 \%$ & $90.80 \%$ & $99.50 \%$ \\
\hline & $\mathrm{SD} \approx$ & 20.80 & 25.66 & 14.68 & 24.82 & 2.24 \\
\hline
\end{tabular}

\section{Comprehension of questions referring to new referents}

Figure 6 shows the performance for the first condition. While adults predominantly responded with "yes" correctly, the children showed substantial difficulty with this condition. 


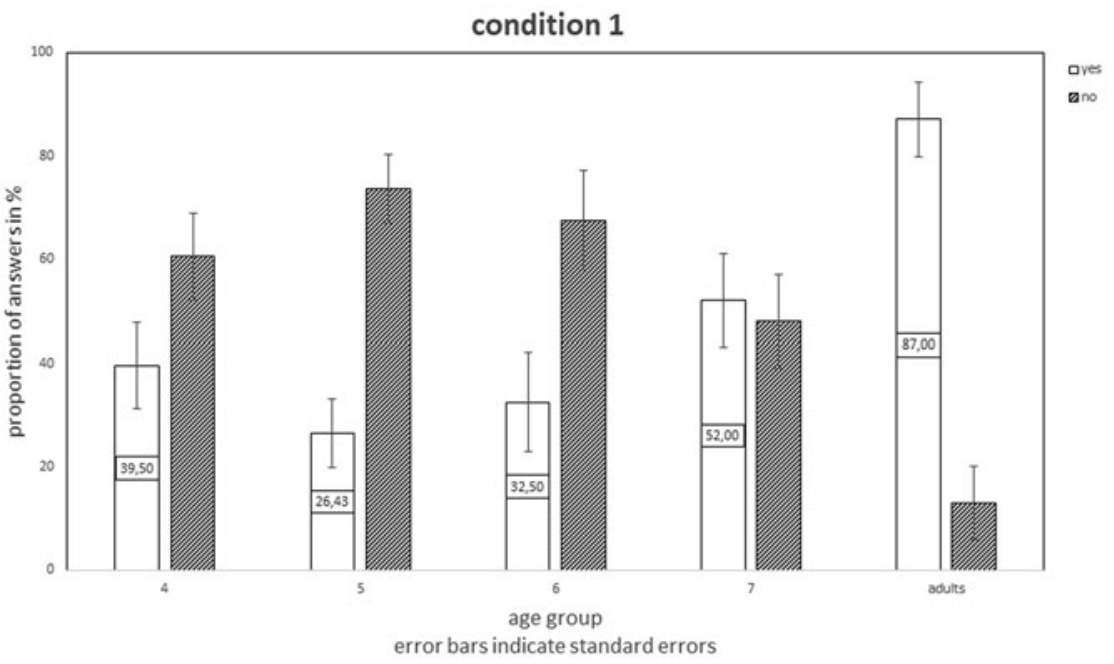

Figure 6. condition 1 (NEW indef $)$

A Kruskal-Wallis-test showed a significant effect of age (chi-square $(4)=24.899$; $\mathrm{p}=0.000$ ). Dunn-Bonferroni post-hoc tests clarified that every group of children differed from the adult group. Four-year-olds vs. adults: $\mathrm{z}=-3.198 ; \mathrm{p}=0.014 ; \mathrm{r} \approx$ 0.33; five-year-olds vs. adults: $\mathrm{z}=-4.530 ; \mathrm{p}=0.000 ; \mathrm{r} \approx 0.47$; six-year-olds vs. adults: $\mathrm{z}=-4.172 ; \mathrm{p}=0.000 ; \mathrm{r} \approx 0.43$; seven-year-olds vs. adults: $\mathrm{z}=-2.957 ; \mathrm{p}=0.031 ; \mathrm{r} \approx$ 0.31. There were no significant differences between any groups of children. In addition, there were no significant correlations between children's age in months and the percentage of correct responses $\left(r_{s}=0.055 ; p=0.300\right.$; one-tailed test).

The bar chart in Figure 7 illustrates the results for the second condition.

A Kruskal-Wallis test revealed an age effect (chi-square $(4)=11.061 ; \mathrm{p}=0.026$ ). Dunn-Bonferroni tests showed that only the four-year-olds and the adults differed significantly from each other $(\mathrm{z}=-3.045 ; \mathrm{p}=0.023 ; \mathrm{r} \approx 0.32)$. Again, there were no significant correlations between the variables "age in months" and the percentages of correct answers $\left(r_{s}=0.137 ; p=0.095\right)$ within the children's groups.

\section{Comprehension of questions referring to given referents}

Figure 8 shows that adults and children clearly preferred the pragmatically felicitous response "yes" for indefinite articles in the sense of an existential quantifier. The results of a Kruskal-Wallis-test yielded an effect of age (chi-square $=23.771 ; \mathrm{p}=$ 0.000). Post-hoc group comparisons were significant for four-year-olds and adults $(\mathrm{z}$ $=-3.516 ; \mathrm{p}=0.004 ; \mathrm{r} \approx 0.36)$; five-year-olds and adults $(\mathrm{z}=-3.573 ; \mathrm{p}=0.004 ; \mathrm{r} \approx$ $0.37)$; five-year-olds and seven-year-olds $(\mathrm{z}=-2.947 ; \mathrm{p}=0.032 ; \mathrm{r} \approx 0.31$; four-year-olds and seven-year-olds $(\mathrm{z}=-2.922 ; \mathrm{p}=0.035 ; \mathrm{r} \approx 0.30)$. A bivariate correlation of the variables "age in months" and the percentages of yes-answers revealed a significant moderate relationship between the mentioned variables $\left(\mathrm{r}_{\mathrm{s}}=\right.$ $0.400 ; \mathrm{p}=0.000$ ): with increasing age, children increasingly preferred the answer "yes".

Figure 9 illustrates the response pattern for the fourth condition. Children as well as adults had no problems to understand that the definite article marks a given referent. 


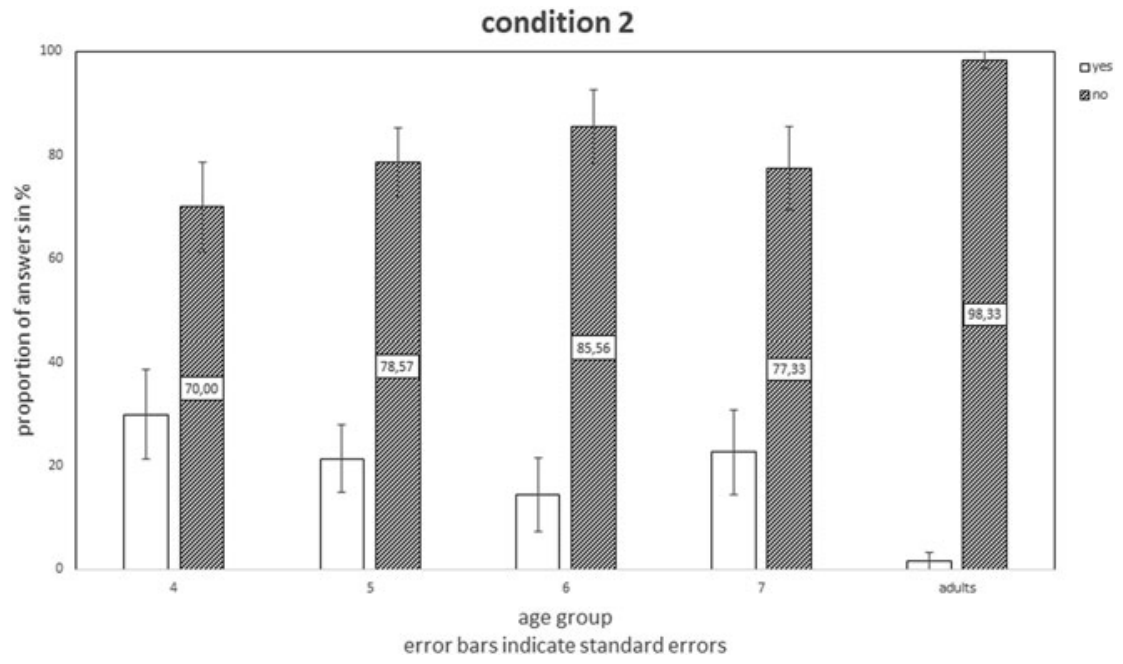

Figure 7. condition $2\left({ }^{*} \mathrm{NEW}_{\text {def }}\right)$

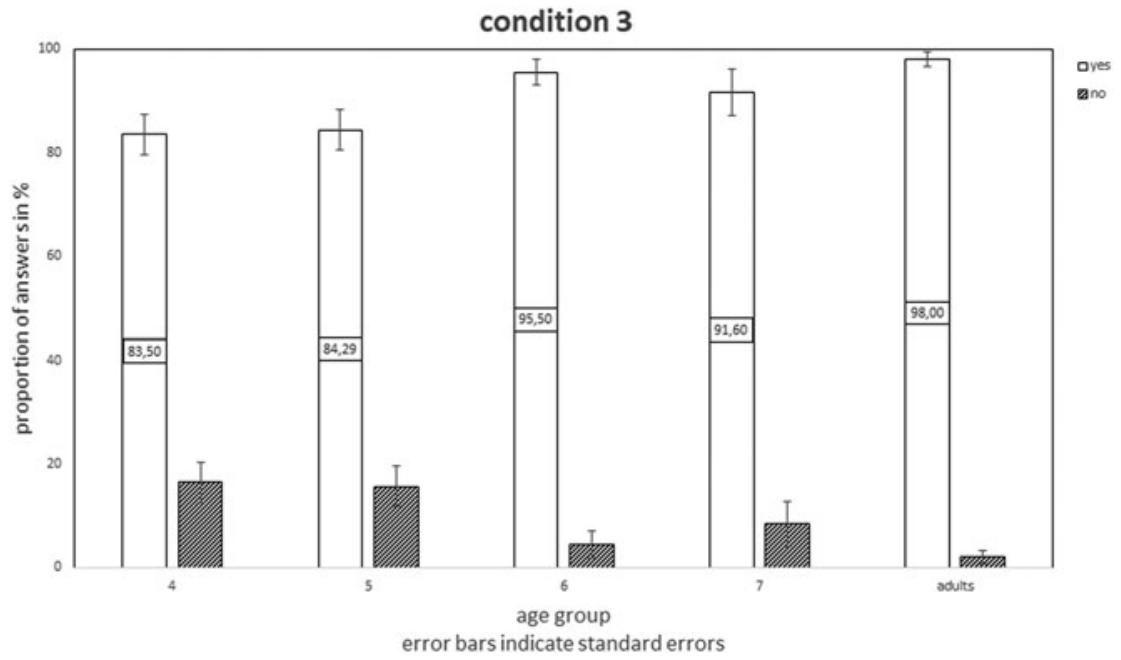

Figure 8. condition $3\left(\left(^{*}\right)\right.$ Given $\left._{\text {indef }}\right)$

Despite the high level of accuracy (see Figure 9), a Kruskal-Wallis-test revealed an effect of age (chi-square $(4)=23.441 ; \mathrm{p}=0.000$ ), and the pairwise comparisons showed that the following groups differed from each other: four-year-olds and adults $(\mathrm{z}=-3.668 ; \mathrm{p}=0.002 ; \mathrm{r} \approx 0.38)$; five-year-olds and adults $(\mathrm{z}=-3.989 ; \mathrm{p}=0.001 ; \mathrm{r} \approx$ $0.40)$. There was a significant moderate relationship between the variables "children's age in months" and the percentages of correct answers $\left(r_{s}=0.334 ; p=0.001\right)$. 


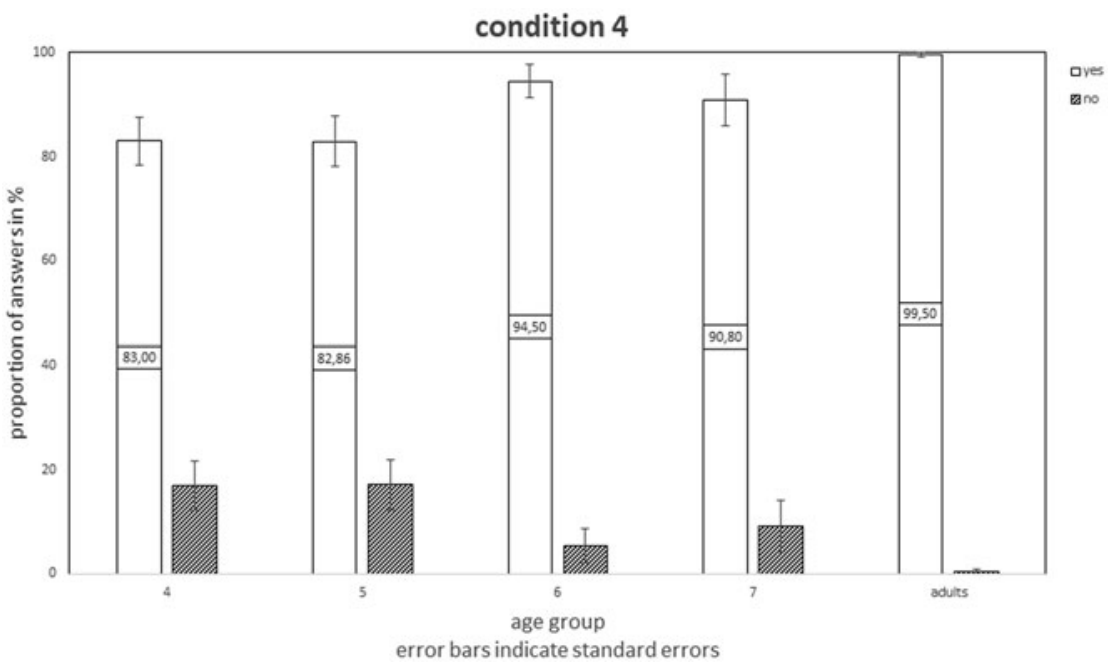

Figure 9. condition $4\left(\right.$ GIVEN $\left._{\text {def }}\right)$

\section{Discussion of experiment 2}

The comprehension experiment investigated how children aged four to seven years in comparison to adults understand indefinite and definite articles as markers of givenness.

The truth-value judgment task showed that children's response patterns were similar to adults in three of the four conditions. The majority of the children seemed to understand that it is not acceptable to refer to a new referent by a definite noun phrase (condition 2); they treated an indefinite article for given referents in the sense of an existential quantifier (condition 3); and they accepted that a definite noun phrase refers to a given referent (condition 4). Age effects during childhood were weak, i.e., there were no massive developmental shifts in the comprehension of articles as markers for the givenness of referents between four and seven years of age.

In contrast, the first condition clearly stands out because, in contrast to the adults, children had substantial difficulty to understand that a speaker is referring to a new referent when using an indefinite article. This finding corroborates the pattern "given better than new" already found in the production experiment. The results of this condition are surprising: the children aged four to six years clearly preferred the incorrect answer "no", whereas the seven-year-olds did not show any preference and might have been guessing. While each of the groups of children differed significantly from the adult group, there were no differences between the groups of children. During the age span from four to seven years, no significant progress seems to take place with respect to the understanding of indefinite articles that serve to introduce new referents.

It is difficult to directly compare the results of the present comprehension study to those of previous studies since different languages were investigated, diverging methods used and partly distinct age groups tested. However, it is plausible to compare our results for comprehension to those obtained by van Hout et al. (2010) due to the similar design of the studies. With respect to the comprehension of indefinite articles 
serving to introduce new referents, the children in the van Hout et al. (2010) study $(3 ; 1-$ $5 ; 8)$ accepted at $92 \%$ that an indefinite article is used to refer to a new referent and at $80 \%$ that a definite article is used for this purpose. So, the children didn't seem to make a clear distinction here. In our study, on the contrary, the children accepted only at $\approx$ $37 \%$ (four-year-olds), $\approx 27 \%$ (five-year-olds), $\approx 31 \%$ (six-year-olds) and $52 \%$ (seven-year-olds) that an indefinite article refers to a new referent. But they predominantly rejected sentences in which a definite article is used to refer to a new referent $(\approx 73 \%-\approx 88 \%)$. Hence, the participants in the present study seemed to make the distinction in question.

With regard to problems in comprehending indefinite articles serving to introduce new referents, several accounts have been put forward as explanations: Maratsos (1976) argues with the semantics of the indefinite article: it can either be interpreted as referring to a new member of the class or to any member of the class. Participants interpreting the indefinite article as referring to any member will probably choose any referent of the class and not necessarily a new one. However, this account cannot explain why more than half of the children under the age of seven have chosen the incorrect answer "no" in the condition NEWindef. Van Hout et al. (2008) as well as van Hout et al. (2010) argue within optimality theory in order to explain comprehension problems with indefinite articles. Unidirectional optimality theory considers the hearer perspective in the interpretation process. For a listener reasoning unidirectionally, there is only one winner for the optimal meaning for interpreting the definite article, namely "determined reference". But with respect to indefinite articles, there are two equal winners, "determined referent" and "non-determined referent", which leads to the indefinite article being ambiguous. Bi-directional optimality theory, on the other hand, determines the optimal candidate in both speaker and hearer perspectives. Bi-directional reasoning leads to the disambiguation of the indefinite article. Hence, it could be claimed that the children in the present study lack bi-directional reasoning which leads to guessing behaviour. However, the children younger than seven years are not guessing in the present study; rather, they predominantly choose the incorrect answer "no" in the condition NEWindef. Therefore, the argumentation within optimality theory does not fully explain the observed results in the present study either.

Existing accounts have mostly considered production and comprehension separately. What is desirable is an account that covers the pattern 'given better than new' in production as well as comprehension. Such an account will be proposed in the next section.

\section{General discussion}

The present study investigated the production and comprehension of indefinite and definite articles as markers of the givenness status new and given in typically developing German-speaking children and an adult control group. Three research questions were addressed: we were interested in how the ability to produce (question 1) and understand (question 2) indefinite and definite articles serving as markers of givenness develops, whether the performance changes with age and whether it differs from the adults' performance. Thirdly, we wanted to find out whether one reference type (new or given) is acquired earlier or mastered more easily than the other.

With respect to the first two questions, the main finding was that no age-related changes were observable in the tested age-span from four to seven years, neither for 
production nor for comprehension. However, the accuracy scores of each group of children differed significantly from those of the adult control group, except for the reference to given referents.

The differential performance for definite and indefinite articles brings us to the third central question regarding a developmental sequence of both givenness status. The main finding of both experiments was that children performed nearly adult-like with respect to the production and comprehension of definite articles coding given referents, but showed significantly more problems than adults with regard to the adequate production and comprehension of indefinite articles serving to introduce new referents. The results of both experiments provide clear evidence for the pattern 'given better than new'.

As the discussion sections of the two experiments have shown, several accounts have been put forward in order to explain findings in production and comprehension separately. None of the existing accounts could fully explain the results of the present study, but the perspective-taking account seemed to be plausible. In order to produce and understand indefinite and definite articles indicating the givenness status of referents adequately, an individual does not only have to acquire the forms of the articles, but also the cognitive capacity to recognize that another person's (i.e., the hearer's) mental state can differ from one's own. Linguistic and cognitive skills have to interact with regard to the acquisition of indefinite and definite articles in the context of information structure. As mentioned before, children participating in the present study ranging from four to seven years are supposed to have acquired theory of mind capacities by that age; therefore, limitations in perspective taking cannot be the only factor explaining our data. We rather assume that the tasks of our studies were rather complex and required the coordination of social cognition and linguistic knowledge at the same time in order to successfully produce and interpret indefinite and definite articles as markers of givenness.

Alternatively, we suggest another account that may be capable to explain the observed pattern 'given better than new' by adopting a theory which has been shown to be useful to explain areas of difficulties in acquisition that may arise from conflicting information in the language input. The competition model, put forward by Bates and MacWhinney (1987), suggests that children make use of different cues in order to acquire certain constructions and weight them in the case that the cues are in conflict. Furthermore, it is assumed that cues vary with regard to their availability (e.g., frequency of occurrence), their consistency in serving a specific function (i.e., cue reliability), and the complexity of the cue (cue costs). In production, the acquisition of definite articles might be mastered better than the acquisition of indefinite articles due to higher cue availability, higher cue reliability and lower cue costs of definite articles in comparison to indefinite ones: as shown in the theoretical background, there is stable empirical evidence that definite articles appear more frequently in the input (high cue availability), they reliably serve the function to maintain reference (high cue reliability), and they lack ambiguity (low cue costs). The indefinite article, on the other hand, is characterized by several disadvantages: the cue costs are higher because of the ambiguity of indefinite articles which can be used to introduce new referents and to refer anaphorically to given referents when used as an existential quantifier. In addition, the input frequency (cue availability) is lower for indefinite articles than for definite ones. The competition model can not only explain the results in production, but also those in the comprehension study. We hypothesise that the conflicting cues that are active in 
condition $1\left(\mathrm{NEW}_{\text {indef }}\right)$ of the truth-value-judgment task are the pragmatic expectation of co-reference between an introduced referent and the topic of the directly following sentence, the frequency of occurrence and the complexity of ambiguous functions of the indefinite article. It is likely that children typically experience that a referent introduced in a first sentence will become the topic of the immediately following sentence (Look, there is an $\mathbf{X}$. The $\mathbf{X}$ is Ying). In the condition NEWindef of the truth-value judgment task, this pragmatic expectation that an introduced referent will be the topic of the discourse gets in conflict with the indefinite article used in the second sentence referring to a new referent. The attentional shift from the expected given to the expressed new referent may be further impeded by the fact that indefinite articles can also refer to given referents when used as an existential quantifier. It is probably for this ambiguous function of indefinite articles (cue costs) and the reliability of maintaining reference to the introduced referent as topic in a discourse (cue reliability) that leads to the misinterpretation of the referents denoted by an indefinite article. The pragmatic cue outweighs the reading of the indefinite article. The adults, on the other hand, weight the cue that an indefinite article refers to a new referent higher than the pragmatically motivated ban on reference shift.

Further examples in the literature show that the competition model is capable to explain different language processing strategies in children and adults. For instance, Dittmar and colleagues suggest that children until the age of seven interpret semantic roles of German noun phrases on the basis of word order cues rather than case markers (Dittmar, Abbot-Smith, Lieven \& Tomasello, 2008), a cue hierarchy that is reversed in adults' sentence processing. It is remarkable that children tend to start with the acquisition of the prototypical case in which different cues converge and not by attending a single cue earlier than the other. In an intermediate stage of acquisition, however, a weighing of cues is visible. The results of the present study point to a comparable development in the weighting of conflicting cues.

The current study's contribution to the relevant research field is twofold: first, the study provides empirically based information concerning the acquisition of indefinite and definite articles serving as markers of givenness in German, a language so far mostly neglected; second, the study adds new data to the heterogenous picture about the acquisition of articles indicating the givenness status of referents in different Indo-European languages.

It has to be left open for future research at what age children's performance becomes adult-like with respect to the understanding and production of indefinite articles for new referents. Furthermore, as an offline task, the present comprehension experiment does not give insights in the real-time processing of indefinite and definite articles. The triangulation of the results of the present truth-value-judgment task with an eye-tracking study is in our view a very promising pathway for future research.

Acknowledgments. The reported study was financially supported by scholarships from the Konrad Adenauer Foundation and the "Kölner Gymnasial- und Stiftungsfonds" to the first author. We thank the schools and daycare centres for their cooperation, the parents who gave their written consent, and the children and adults participating in the study.

\section{References}

Ariel, M. (1988). Referring and accessibility. Journal of Linguistics, 24(1), 65-87. 
Ariel, M. (1990). Accessing noun-phrase antecedents. London: Routledge.

Armon-Lotem, S., \& Avram, I. (2005). The autonomous contribution of syntax and pragmatics to the acquisition of the Hebrew definite article. In A. M. Di Sciullo (Ed.), UG and External Systems: Language, brain and computation, 171-183. Amsterdam: John Benjamins.

Bates, E., \& MacWhinney, B. (1987). Competition, variation, and language learning. In B. MacWhinney (Ed.), Mechanisms of language acquisition, 157-193. Hillsdale: Lawrence Erlbaum.

Baumann, S., \& Riester, A. (2012). Referential and lexical givenness: Semantic, prosodic and cognitive aspects. In G. Elordieta \& P. Prieto (Eds.), Prosody and meaning (pp. 119-161). Berlin: de Gruyter.

Bittner, D. (1997). Entfaltung grammatischer Relationen im NP-Erwerb: Referenz. Folia Linguistica, 31(34), 255-283.

Boersma, P., \& Weenink, D. (2016). Praat: Doing phonetics by computer. [Computer program]. Version 6.0.19. Retrieved from http://www.praat.org/.

Bulheller, S., \& Häcker, H. (2006). Coloured Progressive Matrices. Von J. C. Raven, J. Raven \& J. H. Court. Frankfurt am Main: Pearson Assessment.

Chafe, W. L. (1976). Givenness, contrastiveness, definiteness, subjects, topics, and point of view. In C. N. Li (Ed.), Subject and topic (25-55). New York: Academic Press.

Chailleux, M. (2017). L'acquisition des déterminants définis et indéfinis: Une étude pilote de production induite en français (Unpublished master's thesis). University of Tours, Tours, France.

Clahsen, H. (1984). Der Erwerb von Kasusmarkierungen in der deutschen Kindersprache. Linguistische Berichte, 89, 1-31.

de Cat, C. (2011). Information tracking and encoding in early L1: linguistic competence vs. cognitive limitations. Journal of Child Language, 38(4), 828-860.

Dittmar, M., Abbot-Smith, K., Lieven, E., \& Tomasello, M. (2008). German children's comprehension of word order and case marking in causative sentences. Child Development, 79(4), 1152-1167.

Emslie, H. C., \& Stevenson, R. J. (1981). Pre-school children's use of the articles in definite and indefinite referring expressions. Journal of Child Language, 8(2), 313-328.

Grimm, H. (2001). Sprachentwicklungstest für drei- bis fünfjährige Kinder (SETK 3-5). Göttingen: Hogrefe.

Gundel, J. K. (2015). Pragmatics and information structure. In K. Allan \& K. M. Jaszczolt (Eds.), The Cambridge handbook of pragmatics (pp. 585-598). Cambridge University Press.

Hendriks, P., de Hoop, H., Krämer, I., de Swart, H., \& Zwarts, J. (2010). Conflicts in Interpretation. London: Equinox Publishing.

IDS (2019). FOLK. Informationen zum Forschungs- und Lehrkorpus Gesprochenes Deutsch. Retrieved from < http://agd.ids-mannheim.de/download/flyer_folk_2019_050919.pdf>.

Karmiloff-Smith, A. (1979). A functional approach to child language. A study of determiners and reference. Cambridge University Press.

Kauschke, C., \& Siegmüller, J. (2010). Patholinguistische Diagnostik bei Sprachentwicklungsstörungen (PDSS). 2., völlig überarbeitete Auflage. München: Urban \& Fischer.

Keydeniers, D., Eliazer, J., \& Schaeffer, J. (2017). Definite-indefinite article choice development in Dutch child language. In S. Lestrade, \& B. Le Bruyn (Eds.), Linguistics in the Netherlands 2017, 93-109. Amsterdam \& Philadelphia: John Benjamins.

Krifka, M. (2008). Basic notions of information structure. Acta Linguistica Hungarica, 55(3-4), 243-276.

Krüger, J. (2017). Der Erwerb der Nominalphrasensyntax. Attribution und Schematisierung als syntaktische Verfahren zur Konstruktion objektbezogener Referenz. Siegen: Universi.

Lenhard, A., Segerer, R., Lenhard, W., \& Suggate, S. P. (2015). Peabody Picture Vocabulary Test. 4. Ausgabe. Originalfassung von Lloyd M. Dunn \& Douglas M. Dunn. Frankfurt am Main: Pearson Assessment.

Maratsos, M. P. (1974). Preschool children's use of definite and indefinite articles. Child Development 45 (2), 446-455.

Maratsos, M. P. (1976). The use of definite and indefinite reference in young children: An experimental study of semantic acquisition. Cambridge University Press.

Mills, A. E. (1986). The acquisition of gender. A study of English and German. Berlin: Springer.

Musan, R. (2010). Informationsstruktur. Heidelberg: Winter.

Petermann, F. (2012). Sprachstandserhebungstest für Kinder im Alter zwischen 5 und 10 Jahren (SET 5-10). 2., überarbeitete Auflage. Göttingen: Hogrefe. 
Power, R. J. D., \& Dal Martello, M. F. (1986). The use of the definite and indefinite articles by Italian preschool children. Journal of Child Language, 13(1), 145-154.

Premack, D., \& Woodruff, G. (1978). Does the chimpanzee have a theory of mind? Behavioral and Brain Sciences, 1(4), 515-526.

Preußler, O. (1966). Das kleine Gespenst. Stuttgart: Thienemann.

Prince, E. F. (1992). The ZPG letter: Subjects, definiteness, and information-status. In S. A. Thompson \& W. C. Mann (Eds.), Discourse description: Diverse analyses of a fund raising text, 295-325. Amsterdam \& Philadelphia: John Benjamins.

Roth, A. (2016). Einfluss pragmatischer Fähigkeiten auf die Wahl von Artikeln: Eine Produktionsstudie mit Vorschulkindern (Unpublished bachelor's thesis). University of Potsdam, Potsdam, Germany.

Rozendaal, I. M., \& Baker, A. E. (2008). A cross-linguistic investigation of the acquisition of the pragmatics of indefinite and definite reference in two-year-olds Journal of Child Language, 35(4), 773-807.

Saracho, O. N. (2014). Theory of mind: children's understanding of mental states. Early Child Development and Care 184(6), 949-961.

Schaeffer, J., \& Matthewson, L. (2005). Grammar and pragmatics in the acquisition of article systems. Natural Language \& Linguistic Theory, 23(1), 53-101.

Schafer, R. J., \& de Villiers, J. (2000). Imagining articles: What $a$ and the can tell us about the emergence of DP. In C. S. Howell, S. A. Fish \& T. Keith-Lucas (Eds.), Proceedings of the $24^{\text {th }}$ annual Boston University Conference on Language Development 2 (pp. 609-620). Somerville: Cascadilla Press.

Schröder, A., Gemballa, T., Ruppin, S., \& Wartenburger, I. (2012). German norms for semantic typicality, age of acquisition, and concept familiarity. Behavior Research Methods 44(2), 380-394.

Siegmüller, J., Kauschke, von Minnen, S., \& Bittner, D. (2011). Test zum Satzverstehen von Kindern. Eine profilorientierte Diagnostik der Syntax (TSVK). München: Urban \& Fischer.

Sims, K. M. (1990). Children's knowledge of indefinite and definite reference (Doctoral dissertation). Durham University. Retrieved from http://etheses.dur.ac.uk/6233/.

Szagun, G., Stumper, B., Sondag, N., \& Franik, M. (2007). The acquisition of gender marking by young German-speaking children: Evidence for learning guided by phonological regularities. Journal of Child Language, 34, 445-471.

van Hout, A., de Ree, L., \& de Ree, M. (2008). Dutch children's interpretation of definites and indefinites in discourse. In A. Gavarró \& M. J. Freitas (Eds.), Language acquisition and development. Proceedings of GALA 2007 (pp. 279-289). Newcastle upon Tyne: Cambridge Scholars Publishing.

van Hout, A., Harrigan, H., \& de Villiers, J. (2010). Asymmetries in the acquisition of definite and indefinite NPs. Lingua, 120(8), 1973-1990.

Warden, D. A. (1976). The influence of context on children's use of identifying expressions and references. British Journal of Psychology 67(1), 101-112.

Zehler, A. M., \& Brewer, William F. (1982). Sequence and principles in article system use: an examination of $a$, the and null acquisition. Child Development 53(5), 1268-1274.

Cite this article: Fuchs J, Domahs U, Kauschke C (2021). Information structure in language acquisition. Production and comprehension of (in)definite articles by German-speaking children. Journal of Child Language 48, 55-87. https://doi.org/10.1017/S0305000920000124 